\title{
First tyrannosaurid remains from the Upper Cretaceous "El Gallo" Formation of Baja California, México
}

Brandon R. Peecook, Jeffrey A. Wilson, René Hernández-Rivera, Marisol Montellano-Ballesteros, and Gregory P. Wilson

Acta Palaeontologica Polonica 59 (1), 2014: 71-80 doi: http://dx.doi.org/10.4202/app.2012.0003

We report a complete left fourth metatarsal collected from rocks of the Upper Cretaceous (Campanian) "El Gallo" Formation exposed along the Pacific Ocean near El Rosario, Baja California, México. The metatarsal IV was part of an arctometatarsalian metatarsus, as evidenced by a deep medial notch proximally and extensive articulation for metatarsal III. This condition, along with the U-shape of the proximal end, supports identification as tyrannosauroid. It is assigned to Tyrannosauridae based on features on the posterior surface of the shaft, but finer taxonomic resolution is not possible. Compared to other tyrannosauroids, the metatarsal is relatively short, closely resembling the proportions of the gracile Albertosaurus sarcophagus rather than the much more massive, robust metatarsals of Tyrannosaurus rex. The Baja tyrannosaurid metatarsal is shorter than almost all other tyrannosauroid fourth metatarsals, raising the possibility that it pertains to an immature individual. North American tyrannosauroids are best known from the northern coast of the Western Interior Seaway, as well as less frequently on the southern coast of the seaway in Utah and New Mexico. The new record in Baja marks the first unambiguous skeletal material of a tyrannosaurid both in México and along the Pacific coast.

Key words: Dinosauria, Tyrannosauridae, fourth metatarsal, Campanian, "El Gallo" Formation, Baja California, México.

Brandon R. Peecook [bpeecook@uw.edu] and Gregory P. Wilson [gpwilson@uw.edu ], Department of Biology and Burke Museum of Natural History and Culture, University of Washington, Seattle, Washington 98195, USA; Jeffrey A. Wilson [wilsonja@umich.edu ], Museum of Paleontology and Department of Earth \& Environmental Sciences, University of Michigan, 1109 Geddes Avenue, Ann Arbor, Michigan 48109-1079, USA; René Hernández-Rivera [renedinosaurios@ gmail.com ] and Marisol Montellano-Ballesteros [marmont@servidor.unam.mx], Instituto de Geología, Universidad Nacional Autónoma de México, Ciudad Universitaria, 04510, México City, Distrito Federal, México. 
This is an open-access article distributed under the terms of the Creative Commons

Attribution License (for details please see creativecommons.org), which permits unrestricted use, distribution, and reproduction in any medium, provided the original author and source are credited.

Fof Full text $(487.2 \mathrm{kB})$ 